University of Zurich

Department of Economics

Working Paper Series

ISSN 1664-7041 (print)

ISSN1664-705X(online)

Working Paper No. 14

\title{
Imbalance of World Heritage List: Did the UNESCO Strategy Work?
}

\author{
Lasse Steiner and Bruno S. Frey
}

March 2011 


\title{
IMBALANCE OF WORLD HERITAGE LIST: DID THE UNESCO STRATEGY WORK?*
}

\author{
by \\ Lasse Steiner** \\ University of Zurich \\ and \\ Bruno S. Frey ${ }^{* * *}$ \\ University of Warwick \\ University of Zurich \\ and
}

CREMA - Center for Research in Economics, Management and the Arts, Switzerland

\begin{abstract}
The official intention of the UNESCO World Heritage List is to protect the global heritage. However, the imbalance of the distribution of Sites according to countries and continents is striking. Consequently, the World Heritage Committee launched the Global Strategy for a Balanced, Representative and Credible World Heritage List in 1994. To date, there have not been any empirical analyses conducted to study the impact of this strategy. This paper shows that the imbalance did not decrease and perhaps increased over time, thus reflecting the inability of the Global Strategy to achieve a more balanced distribution of Sites.
\end{abstract}

JEL Classification: Z11, D6, F5, H87

Keywords: UNESCO, international organizations, international political economy, global public goods, world heritage

\footnotetext{
* For helpful suggestions, we are indebted to Paolo Pamini, Reto Cueni, and Peter Egger.

${ }^{* *}$ Research Economist at the University of Zurich, Department of Economics, Wilfriedstrasse 6, CH-8032 Zurich, Switzerland. E-mail: lasse.steiner@econ.uzh.ch

${ }^{* * *}$ Distinguished Professor of Behavioural Science, University of Warwick and Professor of Economics, University of Zurich, Wilfriedstrasse 6, CH-8032 Zurich, Switzerland. He is also Research Director of CREMA. E-mail: bruno.frey@econ.uzh.ch
} 


\section{The World Heritage List}

The World Heritage List compiled by UNESCO has become highly popular. It has been described as "the most effective international legal instrument for the protection of the cultural and natural heritage” (Strasser, 2002, p. 215). Many World Heritage Sites are major attractions for cultural tourism and are icons of national identity (Shackley, 2006:85).

In the 1920s, the League of Nations became aware of the growing threat to the cultural and natural heritage of our planet. However, nothing concrete emerged despite many years of intensive discussions and drafting of reports. In 1959, UNESCO launched a spectacular and successful international campaign to save the Abu Simbel temples in the Nile Valley. In 1966, UNESCO spearheaded an international campaign to save Venice after disastrous floods threatening the survival of the city. In November 1972, the General Conference of UNESCO adopted the Convention concerning the protection of the world cultural and natural heritage at its 17th session in Paris (for a review of the creation of the UNESCO, see e.g.Capello, 1970). The Convention "seeks to encourage the identification, protection and preservation of cultural and natural heritage around the world considered to be of outstanding value to humanity.” It came into force in 1977 and was ratified by 20 nations; the Convention now includes 187 countries, ${ }^{1}$ and the World Heritage List comprises 911 Sites, 704 (or 77 percent) of which relate to culture, 180 to nature, and 27 are mixed, that is, combine cultural and natural heritage.

A striking aspect of the UNESCO List is the highly unequal distribution of Sites according to countries and continents. Although 46 percent of the Sites are in Europe, only 9 percent are in Africa. Only 10 countries have a large number of 20 Sites or more, whereas, on the other hand, there are 38 member countries of the Convention that have no Sites at all. This imbalance of World Heritage Sites according to continents and countries has been present from the beginning, and it has become a subject of major concern within the World Heritage Commission and the World Heritage Centre, UNESCO, and beyond. The Director of the World Heritage Centre, Francesco Bandarin, even went so far as to call the World Heritage List “a catastrophic success” (Henley, 2001).

\footnotetext{
${ }^{1}$ See States of the World Heritage Convention at http://whc.unesco.org/en/statesparties/ (accessed on 14.2.2011). A comprehensive survey of the design and development of the World Heritage Convention and the corresponding institutions (the World Heritage Convention, the World Heritage Committee, and the World Heritage Centre) is provided, for example, in Strasser (2002).

${ }^{2}$ After the 34th ordinary session of the World Heritage Committee, held in Brasília on 25 July-3 August 2010. Only two Sites have been delisted since the implementation of the List.
} 
As a reaction to this imbalance, in 1994, the World Heritage Committee started the Global Strategy for a Balanced, Representative and Credible World Heritage List (hereafter Global Strategy), which intends to raise the share of non-European Sites on the List. Despite this explicit new strategy and intended strong action, "the immediate success of these efforts is questionable” (Strasser 2002, p. 226).

This paper analyses whether, and in which respects, there is an "unbalanced" representation of continents and countries on the World Heritage List. We further address the question of whether the international organization UNESCO is effective in achieving the goal of its own formally ratified resolution. In particular, we test whether the Global Strategy has reached its goal of reducing the inequality of distribution of Sites.

In order to lay the groundwork, Section II briefly discusses the scholarly literature dealing with the issue of the World Heritage and introduces the political actors involved in the nomination process. Section III focuses on various aspects of the selection of the World Heritage Sites. The existing literature usually discusses the strategy for a more balanced World Heritage List and its outcome without referring to empirical evidence. This paper intends to fill the gap by presenting statistics on the highly unequal distribution of Sites across countries and continents (Section IV). The Gini coefficient as a measure of the dispersion of Sites across the world is increasing over time, depicting an increasing concentration of Sites in a few countries. Further, we analyze the UNESCO Global Strategy's objectives of reducing the imbalance between Cultural and Natural Sites as well as reducing the share of European and more developed countries' Sites. The results suggest that the imbalance of the List has not decreased after the introduction of the UNESCO Global Strategy. If anything, it has increased further (Section V). We discuss policy implications and possibilities to reform the List (Section VI). Section VII concludes.

\section{The Background}

\section{Literature}

The central task of the World Heritage Convention - to protect the global public goods of "world cultural and natural heritage" and at the same time to achieve some measure of representatives among continents and countries - links up closely to various topics analyzed in international organizations research. The role of international organizations in the provision of global collective goods or global commons, the respective international cooperation, international regimes and international institutions are examined, for example, 
by Keohane (1967), or Koremenos, Lipson and Snidal (2001). Important work on the dysfunctions in international organizations, is by Grant and Keohane (2005), or MartinezDiaz (2009). The representatives of countries in the international system and the respective organizations are dealt with, for example by Peterson (2010), or Carpenter (2007) in the context of advocacy frameworks and civil society. Political influences in international organizations are the subject of studies by, for example, Oatley and Yackee (2004) or Dreher, Sturm and Vreeland (2009).

In the broader social science literature on World Heritage and on the UNESCO program certain aspects have received special attention: the process of designation with respect to its formal nature, the stakeholder groups participating and their politics (e.g. Cleere, 2006, Harrison and Hitchcock, 2005), the consequences of inclusion in the World Heritage List especially with respect to tourism (e.g. Tunney, 2005, Cochrane and Tapper, 2006), visitor management (e.g. Leask and Fyall, 2006, Shackley, 2006), as well as case studies of individual Sites (e.g for Stonehenge Mason and Kuo, 2006, or for Angkor Wager, 1995). The consequences of being listed, in particular, on the number of visitors frequenting these Sites, are studied, for example, in Yang, Lin, and Han (2009) or Tisdell and Wilson (2002). In economics, only a few works deal with the UNESCO World Heritage, such as the doctoral dissertation by van der Aa (2005), the book by Santagata, De Caro, and Marrelli (2008), and the papers by Frey and Steiner (2011) and Bertacchini, Saccone, and Santagata (2011). An excellent analysis of general heritage issues is provided in Peacock and Rizzo (2008). Other economic analyses mainly evaluate the utility of preserving the past as well as financial consequences (see, for instance Peacock, 1978, Rizzo, 2006). Politico-economic aspects of the List are examined by Frey, Pamini, and Steiner (2011) and Bertacchini and Saccone (2011). The intention of this paper is to provide an international, empirical analysis of the distribution of Sites and the effectiveness of the international institution UNESCO in reaching its stated goals.

\section{Nomination Process}

The advisory bodies to the World Heritage Committee used a somewhat ad hoc method to determine the Sites to be initially included on the List. The Convention's criterion of "outstanding value to humanity" is noble but proved to be almost impossible to define clearly. An important development has been the establishment of 10 criteria for inclusion in 
the World Heritage List, which are listed in detail in the Operational Guidelines for the Implementation of the World Heritage Convention (UNESCO, 2005) and accessible online (see http://whc.unesco.org/en/criteria/). Nominated Sites must meet at least one of the 10 criteria, which are applied in connection with three comprehensive aspects: uniqueness, historical authenticity, and integrity. If a Site meets at least one cultural and one natural criterion, the property's classification is a mixed Site. Six criteria refer to Cultural and four to Natural Sites. The former must "represent a masterpiece of human creative genius" (Criterion i). The latter should “contain superlative natural phenomena or areas of exceptional natural beauty and aesthetic importance” (Criterion vii). ${ }^{3}$

The composition of the World Heritage List is the outcome of actions by three different bodies: the state parties that nominate the Sites, the two advisory boards that evaluate and propose the Sites for inscription, and the Committee that formally decides on inclusion in the List.

The World Heritage Committee meets once a year and consists of representatives from 21 of the member countries. The General Assembly elects the members of the Convention for terms of up to six years. The intention of the Convention is an equitable representation of the world's regions and cultures on the Committee (Art. 8 [2]). However, the Convention nowhere specifies the means to achieve this goal. The Committee is the final decision-making body whose responsibilities include the World Heritage List, the List of World Heritage in Danger, administering the World Heritage Fund, and deciding on financial assistance. Member governments must propose the Sites to be included on the List. Mayors, district governments, or heritage experts may only make proposals for inclusion on a tentative list. Official nomination of a Site occurs only when a country hands in a complete nomination document. The World Heritage Convention differs from many other international conventions because all substantive powers are designated to the Committee and not the General Assembly. The Heritage Committee is advised by the International Council on Museums and Sites (ICOMOS) for Cultural Sites, by the International Union for Conservation of Nature (IUCN) for Natural Sites, and by the International Centre for the Study of the Preservation and Restoration of Cultural Property (ICCROM). It has been claimed, "The scrutiny of these systems by the two Advisory Boards is now rigorous...." (Cleere, 2006:xxii).

\footnotetext{
${ }^{3}$ Appendix I of the Operational Guidelines contains the full list of criteria, which is repeated in the Appendix to this paper.
} 


\section{Selection Aspects of the World Heritage List}

From the point of view of political economy, it may be argued that the selection of the Sites is questionable because it is subject to rent-seeking by experts and politicians (Buchanan, 1980, Frey, 1984, Frey, Pamini and Steiner., 2011). Politicians in their respective countries and expert representatives on the advisory groups ICOMOS and IUCN strongly influence the selection of what Cultural and Natural Sites should be on the List. In most cases, the Committee follows the experts' recommendations. Technical experts rely on their knowledge as art historians and conservators, but "the concept ... has never been the object of a truly operational definition” (Musitelli, 2002 : 329).

Some scholars go so far as to question the legitimacy of the List. Meskell (2002) argues that the concept of World Heritage is flawed by the fact that it privileges an idea originating in the West, which requires an attitude toward material culture that is distinctly European in origin. Affluent countries seem to have benefited most from the Convention. According to a Report of the World Commission on Culture and Development, the World Heritage List "was conceived, supported and nurtured by the industrially developed societies, reflecting concern for a type of heritage that was highly valued in those countries” (Olmland, 1997). Moreover, many countries do not have the necessary conservation infrastructure that allows them to prepare nominations to the List at a sufficiently sustained pace to improve its representativeness (Strasser, 2002, pp. 226-227). According to the Convention, the state parties must identify and delineate the property (Art. 3); in addition, they must ensure the identification, protection, conservation, presentation, and transmission to future generations (Art. 4). These requirements put a heavy burden on countries wishing to put a site on the List. In order to avoid a negative decision, state parties often withdraw a nomination if the Committee or its Bureau is likely to decide unfavorably.

Being on the UNESCO List is highly desired by many as it brings prominence and monetary revenue. The attention of donors and for-profit firms are attracted, and there is a positive relationship between the number of World Heritage Sites and the number of tourist arrivals per country (Lazzarotti, 2000, Yang, Lin and Han, 2009). One may even speak of a "heritage industry" (Johnson and Thomas, 1995). Indeed, inclusion on the List is considered to be a great honor for the respective nation and accordingly gets much attention by the press, radio, and TV (Van der Aa, 2005). It has been highly politicized as many political and bureaucratic representatives of countries consider it a worthwhile goal from which they personally profit. Consequently, the selection is subject to political pressures; thus, it is not 
determined solely by the 10 official criteria deemed to be "objective." Although the goal of the whole project is to protect Sites of central importance for humanity, national interests dominate global interest: "The rhetoric is global: the practice is national” (Ashworth and van der Aa, 2006:148). Some countries more actively try to secure Sites to be included on the List. Twenty-one nations participating in the Convention have a seat on the World Heritage Committee. However, these members nominated more than 30 percent of the listed Sites between 1978 and 2004 (Van der Aa, 2005:81). One example of a questionable selection occurred in 1997 when 10 Italian Sites were included on the List all at once and the chair of the Committee was a compatriot at that time. In addition, the location within the country where the Committee holds its annual meeting seems to have an impact on the number and kind of nominations. The meeting in 1997 indeed was held in Naples (Cleere, 1998). Francesco Bandarin, the Director of the World Heritage Centre, acknowledges, "Inscription has become a political issue. It is about prestige, publicity and economic development” (Henley, 2001).

\section{Distribution of Sites}

The distribution of Sites on the List across continents is highly unequal. Forty-seven percent of the Sites are in Europe. ${ }^{4}$ The European predominance is larger for Cultural Sites (54 percent) than for Natural Sites (22 percent). In contrast, (sub-Saharan) Africa has less than 9 percent of all Sites, and the Arabian countries have 7 percent. The Americas and AsiaPacific are better represented with 17 percent and 20 percent, respectively (see Figure 1).

\section{FIGURE 1}

The distribution of Sites across countries is also highly skewed. Some countries in the world have a large number of World Heritage Sites; others have a few Sites, and a considerable number have none. Only 10 countries have a large number of 20 Sites or more. On the other hand, there are 38 countries with no Sites at all. Some of these countries have been a part of the Convention for long time. ${ }^{5}$ A Gini coefficient of 0.55 in 2009 reflects the highly unequal distribution. A completely equal distribution (each country has the same number of Sites or a Gini coefficient of 0 ) could be supported by the argument that every country should have the same importance with respect to its contribution to the heritage of

\footnotetext{
${ }^{4}$ Continents follow the UN definition.

5 For example, Guyana since 1977 or Monaco since 1978; however, larger countries such as Jamaica (since 1983) or countries with an important heritage, like Bhutan with its Djongs (since 2001), have been disregarded.
} 
humankind. This point of view emphasizes that every country should be of equal worth for an international organization such as the UN and its agency UNESCO. This applies to "culture” in its broadest definition but also to "nature": Each country can be considered to have aspects of Cultural and Natural Sites worth preserving. This particular point of view refrains from any attempt to compare the Sites between countries. Clearly, this is an extreme position because it does not take into account the size of a country as measured by population or geographical extension.

It could be argued that the relevant unit to be considered on the World Heritage List is the size of the population per country rather than countries as such. This view takes into account that China with a population of 1,320 million should have more Sites on the List than a small or very small country, such as Luxemburg (480,000 inhabitants) or Monaco (32,700 inhabitants). This point of view may be considered most appropriate with respect to culture: Each person of the world may be taken to have the same capacity to produce cultural goods. These goods may be of extremely different types and forms and would certainly not correspond to what are sometimes called "high" cultures, such as those of classical Egypt, Greece, or Rome. However, we must take into account that the cultural production may have occurred far back in the past when the population size was quite different from today. This aspect varies from country to country, and we therefore focus on World Heritage Sites according to present population size. Taking the distribution according to the population as a reference, Europe is still on top with 52 Sites per 100 million persons followed by the Arabian countries, the Americas, and sub-Saharan Africa with 23, 18, and 11 Sites per 100 million inhabitants, respectively. The Asia-Pacific region has much less, five per 100 million inhabitants.

It also could be argued that the "balance" should relate to the size of the country as measured by area in square kilometers. The larger a country, the more likely it is to find some Site worth including on the List. This argument seems to be more convincing for Natural than for Cultural Sites. A large country most likely has more different landscapes than a small one, some of which may fit the UNESCO criteria. The distribution of sites per square kilometer is also clearly headed by Europe with 19 sites per million square kilometers, whereas all other continents possess between four and five (see Frey and Pamini, 2010).

The imbalances in the World Heritage List according to continents and countries have been present from the very beginning. Inequality, of course, does not necessarily mean that the selection is incorrect. However, a strongly unequal selection may indicate that inappropriate aspects play a role. UNESCO accepts this point, and the "imbalance” has 
become a subject of major concern within the World Heritage Commission and Centre, UNESCO, and beyond.

\section{Impact of the UNESCO Strategy}

In 1994, 22 years after the adoption of the Convention, UNESCO determined that the World Heritage List lacked balance in the type of inscribed properties and in the geographical areas of the world represented. "Among the 410 properties, 304 were cultural sites and only 90 were natural and 16 mixed, while the vast majority is located in developed regions of the world, notably in Europe” (see http://whc.unesco.org/en/globalstrategy).

Three objective criteria for a more balanced List are available: the distribution according to Cultural and Natural Sites, the distribution according to a country's development, and the distribution according to continents. The Operational Guidelines stipulate in several propositions that a balance in the number of Cultural and Natural Sites should be achieved. ${ }^{6}$

UNESCO further observed an imbalance with respect to the character of Sites. A global study carried out by ICOMOS from 1987 to 1993 suggested that, in Europe, historic towns, religious monuments associated with Christianity, historical periods, and “elitist" architecture (in relation to vernacular) were all overrepresented on the World Heritage List; whereas, all living cultures, especially "traditional cultures,” were underrepresented.

To support the Global Strategy in achieving greater balance, UNESCO intended to encourage countries to become state parties to the Convention, to prepare tentative Lists, and to advance the nominations of properties from categories and regions currently not well represented on the World Heritage List. UNESCO intends to raise the share of non-European sites as well as the share of living cultures included on the List.

\section{Inequality Over Time}

The UNESCO Strategy intended to lower the imbalance, increase the representativeness, and reduce European dominance. The time has come to evaluate the outcome of the Global Strategy empirically.

A first indicator of the imbalance is the Gini coefficient as a measure of statistical dispersion. As seen in Figure 2, the Gini coefficient of the distribution of World Heritage Sites across countries has risen almost monotonously over time from 0.34 in 1979 to 0.55 in

\footnotetext{
${ }^{6}$ See Operational Guidelines, paras. 6, 15, and 58 (version 2002).
} 
2009. The distribution of Sites is increasingly concentrated in countries that already have many Sites. The calculation does not include countries with no Sites to avoid biases by countries that become members of the Convention and start with no Sites. Another way to reduce the bias produced by new member countries is to include countries with no Sites but only if they have been members of the Convention for at least two years. The minimum amount of time the Committee needs to decide on a nomination is 12 months (Leask and Fyall, 2001). When including the zero observations, the Gini coefficient is higher; it increased from 0.52 in 184 to 0.65 in 2009. However, it is increasing less strongly than the Gini coefficient that does not include countries without Sites. ${ }^{7}$

Another measure of dispersion is the standard deviation of the number of Sites per country. The standard deviation has risen from around 2 to 7.6 with the mean increasing from 1.2 to 4.9 Sites per country in the same time. Here the different calculation methods have little effect on the results. Both dispersion measures suggest that the new UNESCO Strategy clearly did not help to reduce the inequality of the distribution among countries.

\section{FIGURE 2}

The number of Sites on the UNESCO List has continuously grown over time. On average, about 30 properties have been added to the List each year. The growth rate has even accelerated, from 26 Sites per year from 1978-1994 to 36 Sites per year afterward. The World Heritage List now contains over 900 Sites. As shown in Figure 1, today, the European countries hold almost half of all Sites. This European dominance was one of the reasons for launching the Global Strategy. Surprisingly, the number of new European World Heritage Sites per year exhibited a strong increase after 1990, which lasted until the year 2000. Even recently, the European countries have been granted more additional new Sites in almost every year than all of the other continents. Consequently, the share of total Sites belonging to Europe rose even after the introduction of the Global Strategy (see Figure 3).

\section{FIGURE 3}

As argued above, the relevant unit for consideration on the World Heritage List could be the size of the population or area per country. Figure 4 shows the number of total Sites per one million square kilometers for each of the continents.

\footnotetext{
${ }^{7}$ The decrease in the beginning can be explained by the many countries that had no Sites when the Convention was launched but soon obtained at least some Sites.
} 


\section{FIGURE 4}

Europe has by far the most Sites per area, and Europe's number of sites compared to all other continents is increasing over time. Here, we show the development after 1990 when the last major change of the area occurred after the U.S.S.R. joined the Convention in 1988. It is also the most relevant range of time for our analyses. There are no indications that the introduction of the UNESCO Strategy in 1994 had any effect. The European countries also lead the distribution of Sites per person. As shown in Figure 5, in 2007, the European continent had about 50 Sites per 100 million persons, whereas all other continents ranged between five and 23 Sites per 100 million persons.

\section{FIGURE 5}

\section{Distribution According to Cultural and Natural Sites}

The distribution of Sites according to Cultural and Natural Sites is very unequal. Today 77 percent of the Sites are Cultural and only 20 percent Natural. This imbalance clearly favors the European countries, which are more successful in obtaining Cultural Sites than countries from other continents. The Operational Guidelines stipulate that an equal distribution of Cultural and Natural Sites should be achieved. In 1980, the United States’ delegate to the Committee suggested establishing a working group on the balance of Cultural and Natural Sites (Strasser, 2002). One goal of the Global Strategy is to approximate the share of these two types of Heritage Sites. Figure 6 depicts the development of the number of Cultural, Natural, and Mixed Sites. Although the number of Mixed Sites has increased the least, the number of Cultural Sites has increased much faster than the number of Natural Sites. In relative terms, the ratio of Cultural to Natural Sites tends to increase monotonously over time. This reflects an increasing share of Cultural Sites-even after the introduction of the Global Strategy.

\section{FIGURE 6}

\section{Simultaneous Analysis of the Impact of the UNESCO Strategy}

The next step is to investigate the impact of the Global Strategy on the distribution of Sites by simultaneously controlling for different factors. Here, we focus on two factors explicitly mentioned in the Global Strategy: the European predominance and the impact of the development level of a country on the number of Sites. 
First, we perform cross-section regressions to estimate the impact of the continents and GDP per capita (1,000 USD per capita) as a measure for economic development. The dependent variable is the total number of Sites a country had before the Global Strategy (1993) and 14 years later (2007). Because the number of Sites is a count variable, we use negative binomial regressions to estimate the partial correlations. We control for the factors introduced above: area (one million square kilometers) as a proxy for natural potential and population (100 million persons) as a proxy for cultural production potential. As a technical control variable, we add the number of years that a country has been part of the Convention, limiting its potential to get Sites (tenure). Table 1 shows the estimated coefficients for the years 1993 and 2007 and for the new Sites obtained in the period between 1993 and 2007.

\section{TABLE 1}

Although the coefficients of area and population remain similar, the coefficient for tenure decreases, which reflects the increasing number of countries in the Convention. The more years a country has been a member of the Convention, the more Sites it obtains. This relationship was less strong in 2007 than in 1993 because of new member countries with more recent tenure obtaining Sites.

With Europe as a reference category, the coefficients of most continent dummies have not changed in a statistically significant way between 1993 and 2007. Even when controlling for the size of a country and tenure in the Convention, non-European continents did not catch up with Europe in terms of the number of Sites. The only continent that shows a significant change is Asia-Pacific but in the unintended direction: Countries on this continent obtained even fewer Sites compared to Europe than before the Global Strategy was started.

Moreover, the Global Strategy intended to increase the share of Sites in less developed regions. Using GDP per capita as a measure for economic development, the estimated coefficients reveal that the Global Strategy also failed with respect to this objective. Although in 1993, before the introduction of the Global Strategy, the coefficient of GDP per capita was not statistically significantly correlated with the number of Sites, 14 years later the correlation was positive and significant. More developed countries obtained more Sites after the introduction of the Global Strategy. We also estimate the impact of the determinants mentioned above only for the Sites obtained after 1993. The results in Table 1, column (3), support our previous results.

In a second step, we test for a structural break by using the panel structure of the data and introducing a Strategy dummy taking the value one after 1993. Interaction effects of the 
Strategy dummy and the determinants reveal whether the slope of these determinants changed after 1993, which would be an indicator for the success of the Global Strategy. Again, we use the total number of Sites of a country up to a certain year as the dependent variable with panel data structure and random effects. ${ }^{8}$ In the basic setting without interaction effects, the results from the cross-section estimations hold (see Table 2, column (4)).

\section{TABLE 2}

In Table 2, column (5), we introduce interaction effects. The Global Strategy dummy is positive and significant. Sites are almost never delisted, so the Stock is increasing continuously after 1993. The interaction coefficient of the Global Strategy and tenure is negative and statistically significant, which indicates that after the introduction of the Global Strategy the relationship of tenure and total sites is less positive than before (but still positive in absolute terms). This reflects the increasing number of member countries. Because the growth of the List is limited, more countries induce a slower increase of the Stock per country. The interaction term of Strategy and GDP per capita is positive and strongly significant. After the introduction of the Global Strategy, the distribution of sites became increasingly biased towards the more developed countries. The interaction effects with the continent dummies of Africa, the Americas, and the Arabian countries are significant and negative. The distribution of sites became increasingly biased towards the European countries after the introduction of the Global Strategy.

A somewhat different approach is to use the new Sites per year a country gets as a dependent variable. These estimations of the flow of Sites confirm our previous results (see Table 2, column (6)). The only difference is the negative coefficient of tenure. Countries that have been members for a longer time obtain fewer Sites per year. However, in this specification, the only significant interaction-term coefficient is the one of the Global Strategy and tenure (see Table 2, column (7)). This coefficient is positive and significant, indicating that after the introduction of the Global Strategy the more tenured countries obtained relatively more Sites than countries with lower tenure. This is contradictory to the aim of UNESCO to support countries that recently joined the Convention.

Overall, our results indicate that the Global Strategy did not help to increase the balance and representativeness of the List with respect to continents and development. If

\footnotetext{
${ }^{8}$ The total number of Sites in year t is correlated with the number of Sites in year t-1. However, the Random Effects model permits serial correlation in the model error.
} 
anything, the distribution of Sites has become even more biased, considering the objectives set by UNESCO.

\section{Alternatives to Protect Heritage}

\section{Reforming the List}

Some of the shortcomings of the List have been noticed by the Convention and proposals for reform have been discussed. One shortcoming is the unbalanced distribution of Sites, which was the aim of the Global Strategy, as discussed above. UNESCO intends to increase the representativeness of the List but struggles to find appropriate criteria (e.g., chronological periods, cultural criteria, or regional distribution). However, underrepresented state parties are encouraged to apply to change the composition of the List. Considering the imbalance of the List, UNESCO has developed a priority system, which prefers state parties with no sites. Moreover, the number of sites per country and year is limited to one in an effort to decrease the imbalance (Strasser, 2002). However, these measures have not had a significant effect so far. In addition, van der Aa (2005) proposes opening the nomination process: Every country, organization, or individual should be allowed to nominate sites. Many more sites would be nominated, so the selection process within a country would probably be less biased. However, the evaluation by the Committee would have to be much stricter.

A second major shortcoming is that the number of Sites on the UNESCO List has continuously grown over time. The Convention does not set a numerical limit for the List, and this overextension of the List imposes problems whereby the Committee has to monitor the state of conservation and management of the Sites (Benhamou, 1996). Imposing a time restriction or making a reevaluation after a certain time obligatory would mitigate this problem because it simplifies the delisting of Sites. This "sunset clause" is successfully applied within the "European Diploma for Protected Areas." The Convention discussed this proposal but it received little support. In 2003, a maximum number of total new Sites per year (30) was introduced.

Another suggestion for reform is to introduce an overall maximum number of Sites. By doing so, the problem of overextension is solved. Monitoring the Sites would be facilitated significantly. Sites would be listed according to their quality but also according to their state of maintenance. Compared to the actual situation, a competition for the best protection would arise in order to be listed (Frey and Steiner, 2011). 


\section{Alternative Protection Measures}

A third major shortcoming is the influence of politicians and bureaucrats on the List and the induced distortions by rent-seeking (Frey, Pamini and Steiner, 2011). As a result, the List reflects national instead of global interests (Ashworth and van der Aa, 2006). The World Heritage List's political dimension also makes reform difficult. It is often discussed as if there were no alternative to that procedure. The UNESCO initiative tends to be presented as the only means with which the globe's cultural and natural heritage can be saved (see e.g. Ashworth and van der Aa, 2006, Van der Aa, 2005, Johnson and Thomas, 1995). However, there are in fact viable alternatives. Two relevant alternatives to having a World Heritage List are of particular interest: using the market and making evaluations competitive.

Private markets financed by admission revenue and donations can protect the global heritage. The size of demand should decide which Sites are to be protected. There is little doubt that most of the well-known Sites on the List would not disappear if they were not on it. In the absence of external effects, the market could be trusted to preserve the globe's cultural and natural heritage. Few economists, not to speak of other people, would be prepared to argue that this is the case. Indeed, the global heritage is characterized by strong positive external effects so that markets do not, or insufficiently, function (Peacock and Rizzo, 2008, Towse, 2010). A second possibility of using the market to preserve efficiently the public good of the World Heritage is to introduce World Culture Certificates. At present, some (rich) countries spend a lot of money on the preservation of cultural monuments that are of only secondary importance. At the same time, due to a lack of money in other (poor) countries highly valuable cultural monuments fall into ruins. With regard to the preservation of humankind's cultural goods, this is a waste of resources. The World Culture Certificate scheme would induce nations to spend the money where it produces the greatest effect on preserving world heritage (see Frey and Pamini, 2009).

The second major alternative to protect the global heritage is competing evaluations. The World Heritage Commission is not the only organization providing lists of cultural and natural heritage. Probably, one of the very first lists of major sites is the "Seven Wonders of the Ancient World.” Historian Herodotus made this list around 450 B.C., which served as a popular guidebook among ancient Hellenic tourists. Nowadays, for-profit firms have long since established guides to the major heritage sites, such as 1000 Places to See Before You 
Die (Schultze, 2003). To a significant extent, the corresponding lists overlap with the World Heritage List. ${ }^{9}$

Many countries have extensive national lists of cultural and natural heritage sites to be preserved, such as the Statutory List of Buildings of Special Architectural or Historic Interest from English Heritage, the National Heritage List in Australia, or the Federal Inventory of Landscapes and Natural Monuments in Switzerland. ${ }^{10}$ However, these lists often carry little weight when there are competing claims, and the respective objects are often badly funded. However, some poor countries do not have such national lists and do not have the resources to protect, secure, and preserve their heritage. In that case, the international effort by UNESCO is certainly important and helpful. Although the World Heritage Commission provides practically no funds to help in the preservation effort, inclusion on the List tends to induce foreign nations, NGOs, or sponsoring firms to provide help (Frey and Steiner, 2011).

\section{Conclusions}

The effort of UNESCO through the World Heritage Commission to establish a World Heritage List containing the most treasured Sites of humanity's culture and landscapes constitutes a great step forward towards preserving one of the most important global public goods on our planet. The List now contains more than 900 Sites, and its number has been steadily increasing since its establishment almost 40 years ago.

The selection of Sites, however, is questionable. It is being subject to rent-seeking not only by the national interests pursued by politicians and bureaucrats but also by the commercial heritage industry. To mitigate the high imbalance of the List in 1994, UNESCO launched the Global Strategy for a Balanced, Representative and Credible World Heritage List. Three of the main goals mentioned by the Global Strategy were lowering the overrepresentation of developed countries and the European continent and increasing the share of Natural compared to Cultural Sites.

Although there is some literature about the Global Strategy and the unequal distribution of Sites, there is a lack of empirical evidence evaluating the development of the imbalance, the impact of the Global Strategy, and therewith the effectiveness of this particular international organization to achieve a more balanced distribution. This paper intends to fill this gap. Surprisingly, all indicators suggest that the List, if anything, has

\footnotetext{
${ }^{9}$ The influence presumably goes both ways: The World Heritage Commission certainly consults such books, and these books include what is listed by the Commission.

${ }^{10}$ Lists on a continental level are also possible: On 9 March 2010, the European Commission adopted a proposal to establish a European Heritage Label.
} 
become even more imbalanced since the introduction of the Global Strategy. The share of Cultural to Natural Sites has continued to increase, exacerbating the goal of a balanced distribution of these categories. The Gini coefficient reveals that the distribution of Sites is now more concentrated than ever. The number of sites in Europe compared to the other continents continued to increase after 1993. Moreover, economically more developed countries obtained relatively more Sites. Furthermore, in contrast to the intention of the UNESCO Strategy, countries with more tenure obtain relatively more Sites per year. Possible measures to lower the imbalance of the List include limiting the number of Sites per country and year or opening the nominations to everyone until the imbalance is reduced.

The positive effects of the UNESCO List on the protection of the global heritage cannot be doubted. However, the striking imbalance of the List reflects a biased nomination process. It is very likely that not all Sites deserving this label are a part of the List. The fact that the decision makers of UNESCO itself realized the unequal distribution and launched the Global Strategy supports this view. However, as we show empirically, the Global Strategy was not successful in reducing European predominance. This paper intends to attract attention to the persisting imbalance of the List, and it can serve as a starting point for further discussion about possible reforms to protect our global heritage. 


\section{Appendix}

The first six criteria refer to Cultural Sites:

1) to represent a masterpiece of human creative genius

2) to exhibit an important interchange of human values, over a span of time or within a cultural area of the world, on developments in architecture or technology, monumental arts, town-planning or landscape design

3) to bear a unique or at least exceptional testimony to a cultural tradition or to a civilization which is living or which has disappeared

4) to be an outstanding example of a type of building, architectural or technological ensemble or landscape which illustrates (a) significant stage(s) in human history

5) to be an outstanding example of a traditional human settlement, land-use, or sea-use which is representative of a culture (or cultures), or human interaction with the environment especially when it has become vulnerable under the impact of irreversible change

6) to be directly or tangibly associated with events or living traditions, with ideas, or with beliefs, with artistic and literary works of outstanding universal significance. (The Committee considers that this criterion should preferably be used in conjunction with other criteria)

The last four criteria concern Natural Sites:

1) to contain superlative natural phenomena or areas of exceptional natural beauty and aesthetic importance

2) to be outstanding examples representing major stages of earth's history, including the record of life, significant on-going geological processes in the development of landforms, or significant geomorphic or physiographic features

3) to be outstanding examples representing significant on-going ecological and biological processes in the evolution and development of terrestrial, fresh water, coastal and marine ecosystems and communities of plants and animals

4) to contain the most important and significant natural habitats for in-situ conservation of biological diversity, including those containing threatened species of outstanding universal value from the point of view of science or conservation 
Figure 1

The World Heritage List according to types of heritage and continents 2009



Note: 21 Heritage Sites go across two countries each, one Site goes across 10 countries. This and all further tables count Sites as many times as the number of countries involved. We do not count the Old City of Jerusalem (ID 48) because it is associated with no country. Sites given to the Socialist Federal Republic of Yugoslavia are still counted under Serbia, although they now are listed under Croatia, Macedonia, Montenegro, and Slovenia. Itchan Kala (ID 543) is counted under Russia because in 1990 Uzbekistan still was part of it. We do not count the Bialowieza Forest (ID 33) for Belarus because in 1979 neither Belarus nor the USSR was in the World Heritage Convention. We do not count the Historic Center of Rome (ID 91) for the Holy See because in 1980 it was not yet a member of the World Heritage Convention. Although we are interested into the election process, we include the two delisted Sites (Arabian Oryx Sanctuary in Oman, listed in 1994 and delisted in 2007 ID 654, as well as Dresden Elbe Valley in Germany, listed in 2004 and delisted in 2009 ID 1156).

Source: based on http://whc.unesco.org/en/list (accessed on August 30, 2010). 
Figure 2

Dispersion of World Heritage Sites according to countries 1979-2009

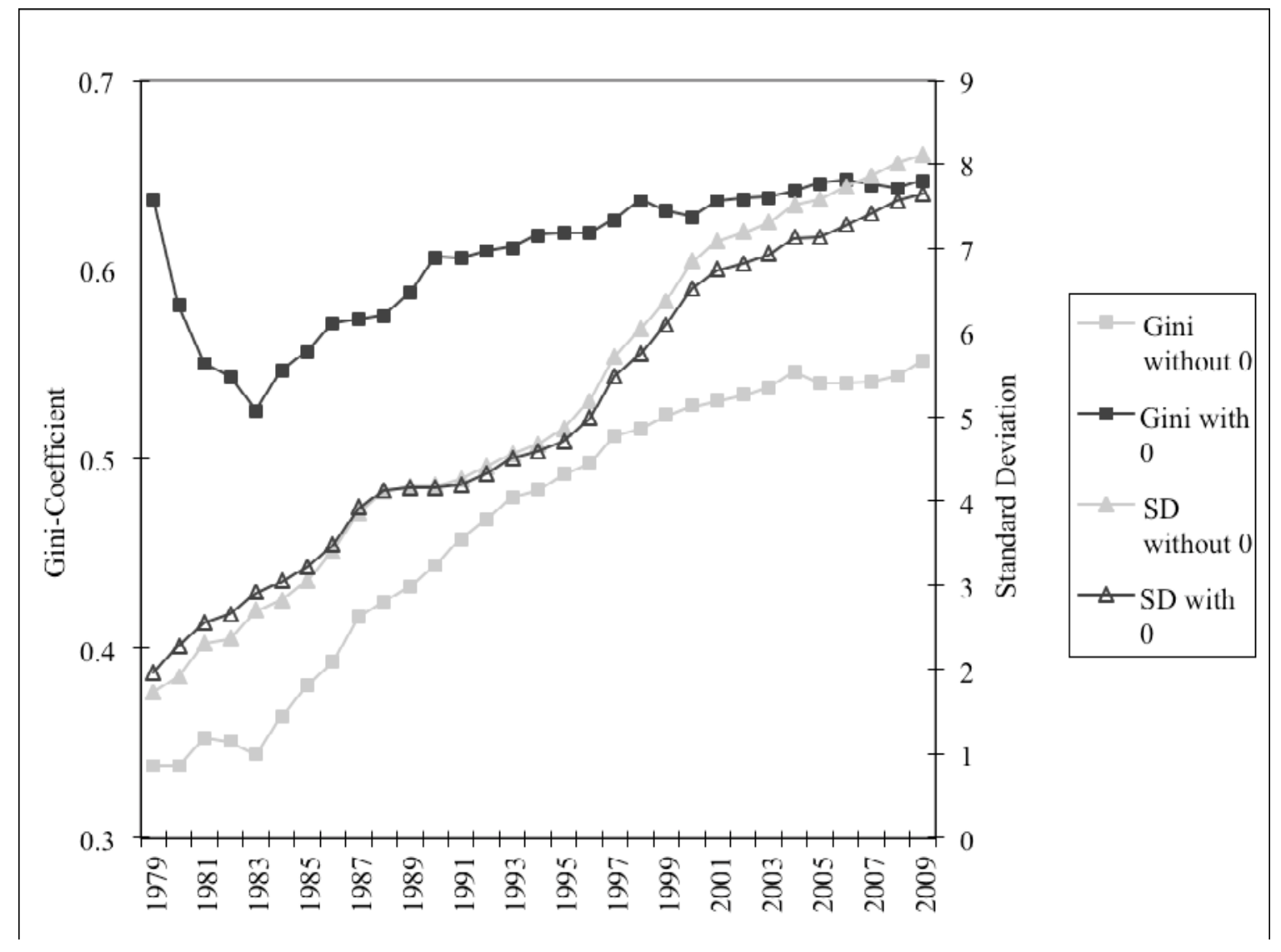


Figure 3

Share of total Sites per continent 1990-2009

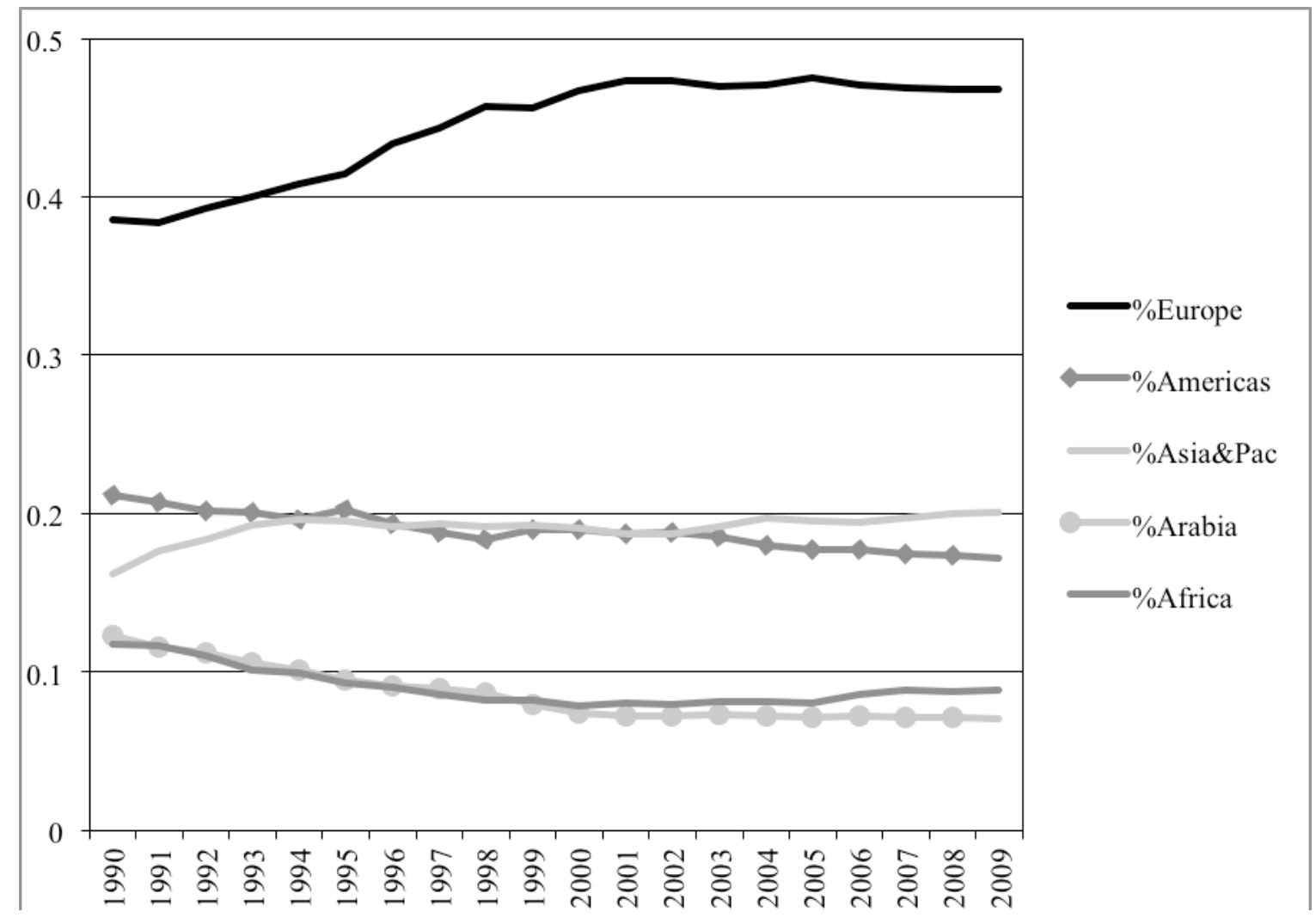


Figure 4

Number of Sites per area and continent 1990-2007

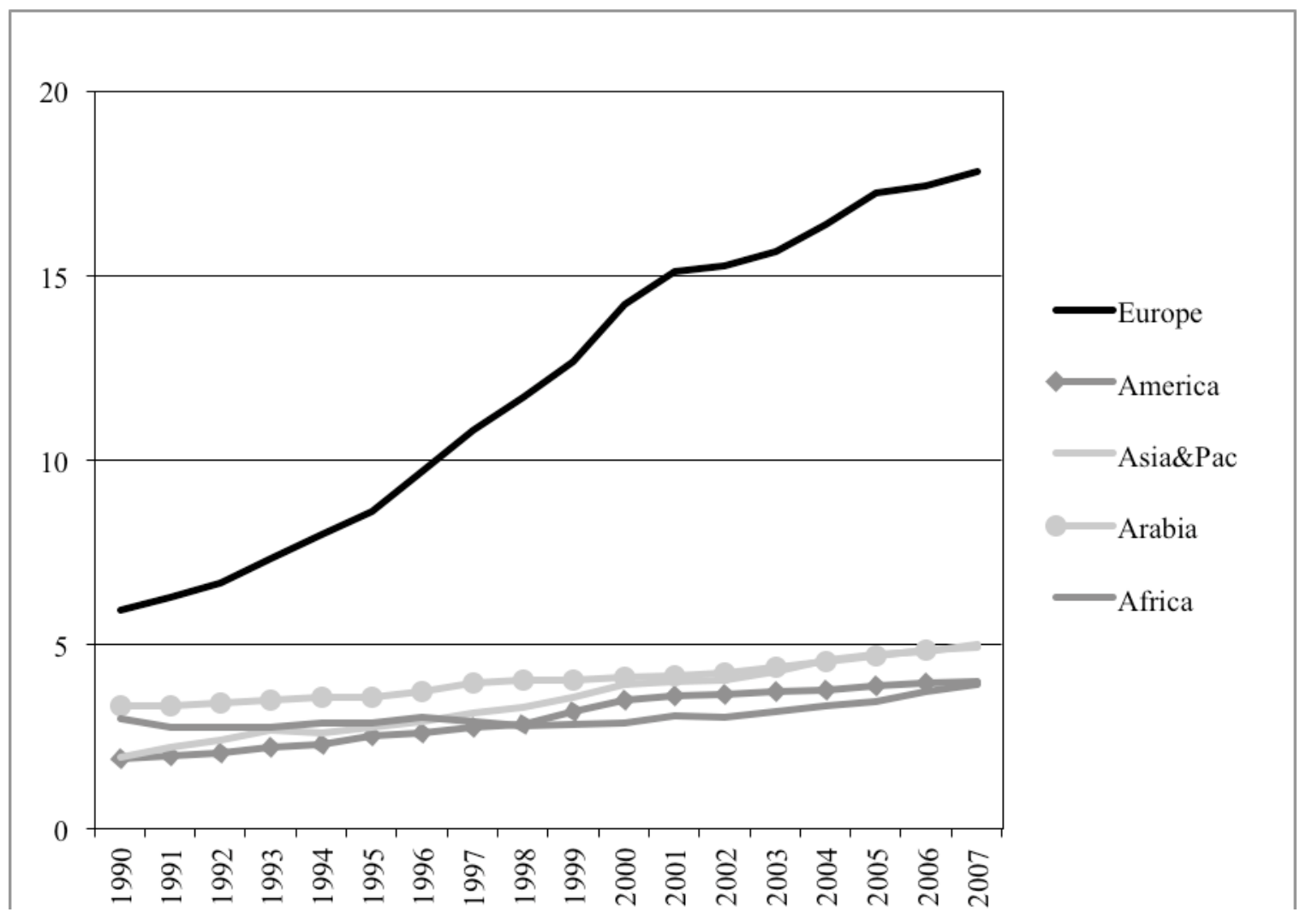


Figure 5

Number of Sites according to population and continent 1990-2007

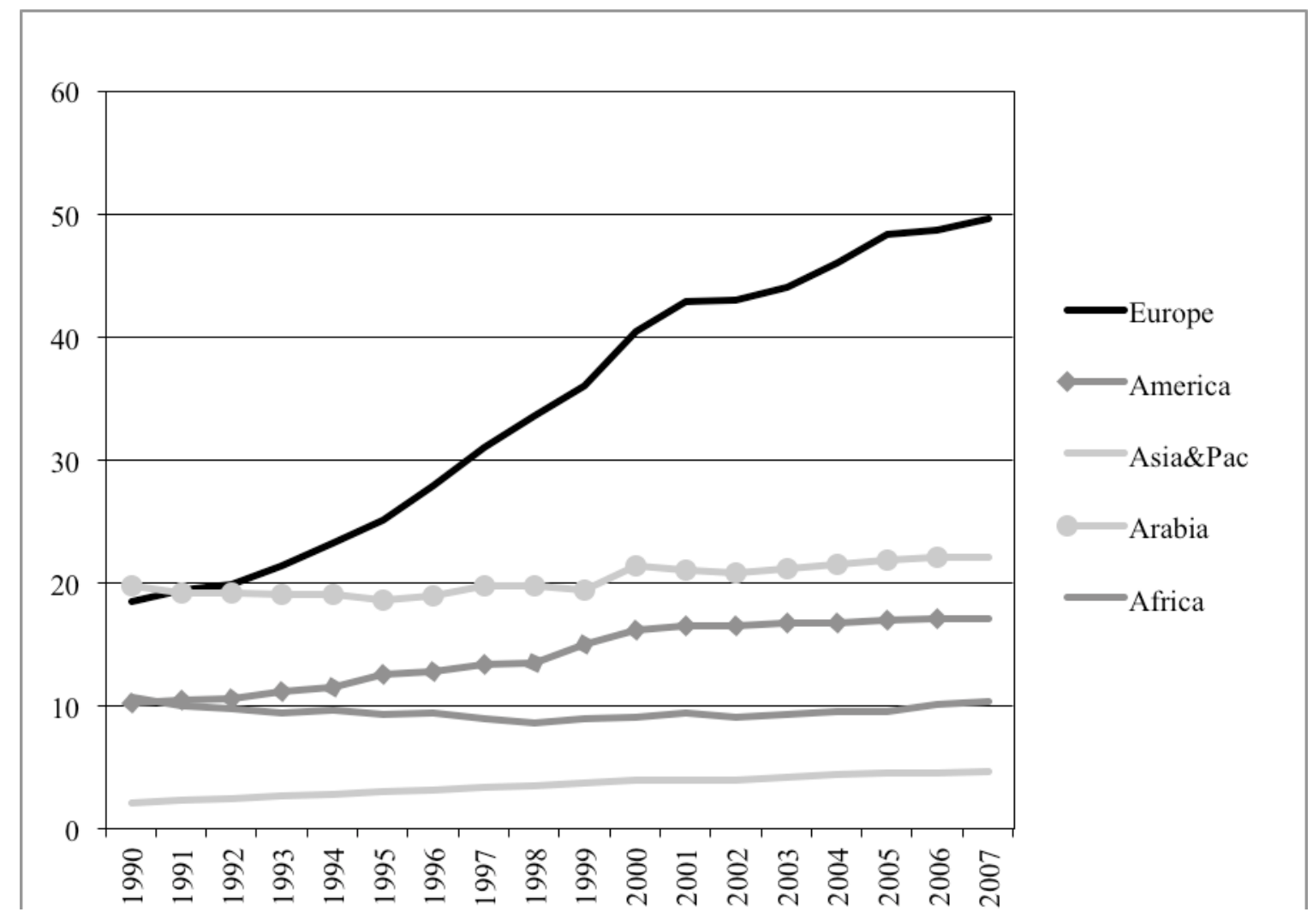


Figure 6

Development of number of Cultural, Natural and Mixed Sites 1990-2009

Zur Anzeige wird der QuickTime ${ }^{\mathrm{TM}}$ Dekompressor ,

benötigt. 
Table 1

Determinants of Inclusion in the World Heritage List

\begin{tabular}{|c|c|c|c|}
\hline & Sites 1993 & Sites 2007 & Sites 1993-2007 \\
\hline & (1) & (2) & (3) \\
\hline \multirow[t]{2}{*}{ AREA } & $0.0803^{* *}$ & $0.0887 * *$ & $0.0950 * *$ \\
\hline & $(2.083)$ & $(2.511)$ & -2.035 \\
\hline \multirow[t]{2}{*}{ POPULATION } & $0.165 * *$ & $0.184 * * *$ & $0.191 * *$ \\
\hline & $(2.275)$ & (3.041) & -2.46 \\
\hline \multirow[t]{2}{*}{ TENURE } & $0.130 * * *$ & $0.0839 * * *$ & $0.0411^{* * *}$ \\
\hline & $(7.150)$ & $(8.147)$ & -3.255 \\
\hline \multirow[t]{2}{*}{ GDPPC } & 0.00858 & $0.0212 * * *$ & $0.0296 * * *$ \\
\hline & $(0.676)$ & $(2.738)$ & -2.933 \\
\hline \multirow[t]{2}{*}{ AFRICA } & $-1.284 * * *$ & $-1.283 * * *$ & $-1.324 * * *$ \\
\hline & $(-4.272)$ & $(-5.479)$ & $(-4.412)$ \\
\hline \multirow[t]{2}{*}{ AMERICA } & $-0.933 * * *$ & $-0.965 * * *$ & $-0.956 * * *$ \\
\hline & $(-3.477)$ & $(-4.416)$ & $(-3.398)$ \\
\hline \multirow[t]{2}{*}{ ASIA-PACIFIC } & $-0.565^{*}$ & $-0.805^{* * *}$ & $-0.942 * * *$ \\
\hline & $(-1.939)$ & $(-3.744)$ & $(-3.476)$ \\
\hline \multirow[t]{2}{*}{ ARABIA } & $-0.999 * * *$ & $-1.084 * * *$ & $-1.554 * * *$ \\
\hline & $(-2.911)$ & $(-3.591)$ & $(-3.500)$ \\
\hline EUROPE & & (reference continent) & \\
\hline \multirow[t]{2}{*}{ Constant } & -0.0930 & -0.145 & 0.173 \\
\hline & $(-0.357)$ & $(-0.550)$ & $(0.546)$ \\
\hline Observations & 127 & 166 & 166 \\
\hline
\end{tabular}

Cross-section estimations. z-statistics in parentheses: ${ }^{* * *} \mathrm{p}<0.01,{ }^{*} \mathrm{p}<0.05,{ }^{*} \mathrm{p}<0.1$ 
Table 2

Testing for a Structural Break in 1994 - Panel Estimations of Stock and Flow Determinants

\begin{tabular}{|c|c|c|c|c|}
\hline VARIABLES & $\begin{array}{c}\text { Total Sites up to year } \\
\mathrm{t}\end{array}$ & $\begin{array}{c}\text { Total Sites up to year } \\
\mathrm{t}\end{array}$ & Total Sites per year & Total Sites per year \\
\hline & (4) & (5) & (6) & (7) \\
\hline \multirow[t]{2}{*}{ AREA } & $0.207 * * *$ & $0.230 * * *$ & $0.125^{* * *}$ & $0.141^{* * *}$ \\
\hline & $(2.787)$ & $(2.858)$ & $(4.102)$ & $(4.073)$ \\
\hline \multirow[t]{2}{*}{ POPULATION } & $0.0805^{* *}$ & 0.0622 & $0.149 * * *$ & $0.120 * *$ \\
\hline & $(2.572)$ & (1.108) & $(3.386)$ & $(1.982)$ \\
\hline \multirow[t]{2}{*}{ TENURE } & $0.0588 * * *$ & $0.121^{* * *}$ & $-0.0157 * * *$ & $-0.0377 * * *$ \\
\hline & (33.92) & $(29.12)$ & $(-2.769)$ & $(-2.625)$ \\
\hline \multirow[t]{2}{*}{ GDPPC } & $0.0129 * *$ & -0.00971 & $0.0231 * * *$ & 0.0197 \\
\hline & $(2.364)$ & $(-1.057)$ & (3.122) & $(1.470)$ \\
\hline \multirow[t]{2}{*}{ AFRICA } & $-1.374 * * *$ & $-1.312 * * *$ & $-1.118 * * *$ & $-0.891 * * *$ \\
\hline & $(-4.878)$ & $(-4.280)$ & $(-5.318)$ & $(-2.879)$ \\
\hline \multirow[t]{2}{*}{ AMERICA } & $-1.047 * * *$ & $-1.081^{* * *}$ & $-0.724 * * *$ & $-0.498 * *$ \\
\hline & $(-3.425)$ & $(-3.299)$ & $(-3.788)$ & $(-1.990)$ \\
\hline \multirow[t]{2}{*}{ ASIA-PACIFIC } & $-0.946 * * *$ & $-0.967 * * *$ & $-0.891 * * *$ & $-0.642 * *$ \\
\hline & $(-3.264)$ & $(-3.139)$ & $(-4.531)$ & $(-2.171)$ \\
\hline \multirow[t]{2}{*}{ ARABIA } & $-0.959 * * *$ & $-0.981 * *$ & $-0.989 * * *$ & $-0.675 * *$ \\
\hline & $(-2.668)$ & $(-2.558)$ & $(-3.985)$ & $(-1.982)$ \\
\hline EUROPE & \multicolumn{4}{|c|}{ (reference continent) } \\
\hline \multirow{2}{*}{ STRATEGY } & & $0.924 * * *$ & & -0.00749 \\
\hline & & $(12.50)$ & & $(-0.0312)$ \\
\hline \multirow[t]{2}{*}{ Strat*Area } & & 0.00211 & & -0.0266 \\
\hline & & $(0.249)$ & & $(-1.064)$ \\
\hline \multirow[t]{2}{*}{ Strat*Pop } & & 0.00622 & & 0.0364 \\
\hline & & $(0.428)$ & & (0.819) \\
\hline \multirow[t]{2}{*}{ Strat*Tenure } & & $-0.0757 * * *$ & & $0.0278 *$ \\
\hline & & $(-18.63)$ & & (1.759) \\
\hline \multirow[t]{2}{*}{ Strat*Gdppc } & & $0.00956 * * *$ & & 0.00302 \\
\hline & & (2.689) & & $(0.252)$ \\
\hline \multirow[t]{2}{*}{ Strat*Africa } & & $-0.350 * * *$ & & -0.378 \\
\hline & & $(-4.261)$ & & $(-1.118)$ \\
\hline \multirow[t]{2}{*}{ Strat*America } & & $-0.134 * *$ & & -0.409 \\
\hline & & $(-2.005)$ & & $(-1.641)$ \\
\hline \multirow[t]{2}{*}{ Strat*Asia } & & -0.0968 & & -0.371 \\
\hline & & $(-1.237)$ & & $(-1.230)$ \\
\hline \multirow[t]{2}{*}{ Strat*Arabia } & & $-0.164^{*}$ & & -0.545 \\
\hline & & $(-1.948)$ & & $(-1.375)$ \\
\hline \multirow[t]{2}{*}{ Constant } & 17.01 & 16.91 & -0.246 & -0.228 \\
\hline & $(0.145)$ & (0.139) & $(-1.266)$ & $(-0.883)$ \\
\hline Observations & 3,458 & 3,458 & 3,458 & 3,458 \\
\hline Number of id & 176 & 176 & 176 & 176 \\
\hline Log likelihood & -5339 & -5116 & -1818 & -1813 \\
\hline
\end{tabular}

Dependent variable (4) \& (5): Accumulated total number of sites of per country up to year t.

Dependent variable (6) \& (7): Total number of new Sites per Country in year t.

Random effects estimates 1978-2007.

z-statistics in parentheses: $* * * \mathrm{p}<0.01,{ }^{* *} \mathrm{p}<0.05$, * $\mathrm{p}<0.1$ 


\section{References}

Ashworth, G.J. and van der Aa, B.J.M. (2006). Strategy and policy for the world heritage convention: goals, practices and future solutions. in: Anna Leask and Alan Fyall (eds.) Managing World Heritage Sites. London: Elsevier: 147-158.

Benhamou, F. (1996). Is Increased Public Spending for the Preservation of Historic Monuments Inevitable? The French Case. Journal of Cultural Economics, 20: 115131.

Bertacchini, E. and Saccone, D. (2011). The Political Economy of World Heritage. Working Paper New Series. Torino: Università di Torino.

Bertacchini, E., Saccone, D. and Santagata, W. (2011). Loving Diversity, Correcting Inequalities: Towards a New Global Governance for the UNESCO World Heritage. International Journal of Cultural Policy, Forthcoming.

Buchanan, J.M. (1980). Rent Seeking and Profit Seeking. in: James M. Buchanan, Robert M. Tollison and Gordon Tullock (eds.) Toward a Theory of the Rent-Seeking Society. Texas: Texas A \& M University Press.

Capello, H.H.K.d. (1970). The Creation of the United Nations Educational, Scientific and Cultural Organization. International Organization, 24: 1-30.

Carpenter, R.C. (2007). Setting the Advocacy Agenda: Theorizing Issue Emergence and Nonemergence in Transnational Advocacy Networks. International Studies Quarterly, 51: 99-120.

Cleere, H. (1998). Europe's cultural heritage from a world perspective. in: ICOMOS UK (ed.) Sustaining the cultural heritage of Europe. London: ICOMOS UK.

Cleere, H. (2006). Foreword. in: Alan Fyall Anna Leask (ed.) Managing World Heritage Sites. London: Elsevier: xxi-xxiii.

Cochrane, J. and Tapper, R. (2006). Tourism's contribution to World Heritage Site management. in: Anna Leask and Alan Fyall (eds.) Managing World Heritage Sites. London: Elsevier: 97-109.

Dreher, A., Sturm, J.-E. and Vreeland, J.R. (2009). Development aid and international politics: Does membership on the UN Security Council influence World Bank decisions? Journal of Development Economics, 88: 1-18.

Frey, B.S. (1984). The public choice view of international political economy. International Organization, 38: 199-223.

Frey, B.S. and Pamini, P. (2009). Making World Heritage Truly Global: The Culture Certificate Scheme. Oxonomics, 4: 1-9.

Frey, B.S. and Pamini, P. (2010). World Heritage: Where Are We? An Empirical Analysis. CESifo Working Paper Series. Munich: IFO.

Frey, B.S., Pamini, P. and Steiner, L. (2011). What Determines the World Heritage List? An Econometric Analysis. Working Paper Series. Zurich: Department of Economics, University of Zurich.

Frey, B.S. and Steiner, L. (2011). World Heritage List: Does it Make Sense? International Journal of Cultural Policy, forthcoming.

Grant, R.W. and Keohane, R.O. (2005). Accountability and Abuses of Power in World Politics. American Political Science Review, 99: 29-43.

Harrison, D. and Hitchcock, M. (2005). The Politics of Heritage. Negotiating Tourism and Conservation. Channel View, Clevedon, UK: Channel View Publications.

Henley, J. ( 2001). Fighting for the Mighty Monuments. Guardian Unlimited.

Johnson, P. and Thomas, B. (1995). Heritage as Business. in: David T. Herbert (ed.) Heritage, Tourism and Society. New York Mansell Publishing: 170-190. 
Keohane, R.O. (1967). The Study of Political Influence in the General Assembly. International Organization, 21: 221-237.

Koremenos, B., Lipson, C. and Snidal, D. (2001). The Rational Design of International Institutions. International Organization, 55: 761-799.

Lazzarotti, O. (2000). Patrimoine et tourisme: Un couple de la mondialisation. Mappemonde, 15: 12-16.

Leask, A. and Fyall, A. (2001). World heritage site designation: Future implications from a UK perspective. Tourism recreation research, 26: 55-63.

Leask, A. and Fyall, A. (2006). Managing World Heritage Sites, Amsterdam: Elsevier

Martinez-Diaz, L. (2009). Boards of directors in international organizations: A framework for understanding the dilemmas of institutional design. The Review of International Organizations, 4: 383-406.

Mason, P. and Kuo, I.-L. (2006). Visitor management at Stonehenge, UK. in: Anna Leask and Alan Fyall (eds.) Managing World Heritage Sites. London: Elsevier: 181-194.

Meskell, L. (2002). Negative Heritage and Past Mastering in Archeology. Anthropological Quarterly, 75: 557-574.

Musitelli, J. (2002). World Heritage, between Universalism and Globalization. International Journal of Cultural Property, 11: 323-336.

Oatley, T. and Yackee, J. (2004). American Interests and IMF Lending. International Politics, 41: 415-429.

Olmland, A. (1997). World Heritage - and the relationship between the global and the local. Department of Archaeology. University of Cambridge.

Peacock, A. (1978). Preserving the past: an international economic dilemma. Journal of Cultural Economics, 2: 1-11.

Peacock, A. and Rizzo, I. (2008). The Heritage Game. Economics, Politics, and Practice, Oxford: Oxford University Press.

Peterson, M. (2010). How the indigenous got seats at the UN table. The Review of International Organizations, 5: 197-225.

Rizzo, I. (2006). Cultural Heritage: Economic Analysis and Public Policy. in: Victor A. Ginsburgh and David Throsby (eds.) Handbook of the Economics of Art and Culture. Amsterdam: Elsevier: 983-1016.

Santagata, W., De Caro, S. and Marrelli, M. (2008). Patrimoni intangibili dell' umanità. Il distretto culturale del presepe Napolitano, Napoli: Guida Editore.

Schultze, P. (2003). 1000 Places to see before you die, New York: Workman Publishing.

Shackley, M. (2006). Visitor Management: Case Studies from World Heritage Sites, Oxford: Butterworth-Heinemann.

Strasser, P. (2002). "Putting Reform Into Action” — Thirty Years of the World Heritage Convention: How to Reform a Convention without Changing Its Regulations. International Journal of Cultural Property, 11: 215-266.

Tisdell, C. and Wilson, C. (2002). World Heritage Listing of Australian Natural Sites: Tourism Stimulus and its Economic Value. Economic Analysis and Policy, 32: 27-49.

Towse, R. (2010). A Textbook of Cultural Economics, New York: Cambridge University Press.

Tunney, J. ( 2005). World Trade Law, Culture, Heritage and Tourism. Towards a Holistic Conceptual Approach. in: David Harrison and Michael Hitchcock (eds.) The Politics of Heritage. Negotiating Tourism and Conservation. Clevedon: Channel View Publications: 90-102.

UNESCO (2005). Operational Guidelines for the Implementation of the World Heritage Convention. http://whc.unesco.org/archive/opguide05-en.pdf. 
Van der Aa, B.J.M. (2005). Preserving the Heritage of Humanity? Obtaining World Heritage Status and the Impacts of Listing, Amsterdam: Netherlands Organization for Scientific Research.

Wager, J. (1995). Developing a strategy for the Angkor World Heritage Site. Tourism Management, 16: 515-523.

Yang, C.-H., Lin, H.-L. and Han, C.-C. (2009). Analysis of international tourist arrivals in China: The role of World Heritage Sites. Tourism Management, 31: 827-837. 